\title{
Molecular mechanism of the role of carbamyl erythropoietin in treating diabetic retinopathy rats
}

\author{
XUEGU XU, YONGHAO CAI and YINFEI YU \\ Department of Pharmacy, The Eye Hospital of Wenzhou Medical University, Wenzhou, Zhejiang 325003, P.R. China
}

Received March 22, 2018; Accepted May 3, 2018

DOI: $10.3892 /$ etm.2018.6167

\begin{abstract}
The aim of the present study was to investigate the therapeutic effects of carbamyl erythropoietin (CEPO) and safflor yellow (SY) in the treatment of rats with diabetic retinopathy (DR) as well as exploring the mechanism of action. Male SD rats were used to establish a diabetes model and streptozotocin-induced retinopathy was also performed in rats. A total of 126 rats with DR were obtained, and model rats were randomly divided into the model $(n=42)$, experimental $(n=42)$ and control $(n=42)$ groups. The rats in the model group were injected with saline, the rats in the experimental group were treated with CEPO, and the rats in the control group were treated with SY. After treatment for 2 weeks, the retinas were harvested for quantitative analysis of the mRNA expression levels of angiogenesis-promoting and -inhibiting molecules, apoptosispromoting and -inhibiting molecules, and oxidative stress pathway-related factors by Reverse transcription-quantitative PCR (RT-qPCR). No significant differences in expression levels of hypoxia-inducible factor- $1 \alpha$ (HIF-1 $\alpha)$, vascular endothelial growth factor (VEGF), angiopoietin (Ang-1), tissue kallikrein (TKLK) and pigment epithelium-derived factor (PEDF) were observed between the experimental and model groups $(\mathrm{P}>0.05)$. The expression levels of apoptosis-promoting molecules $\mathrm{Bcl}-2$ related $\mathrm{X}$ protein (Bax) and cysteine aspartate specific protease (caspase-3) mRNA in the retina of the experimental group was significantly lower than those in the control group $(\mathrm{P}<0.05)$. The expression levels of Bcl-2 and survivin mRNA were significantly higher in the experimental group than in the control group $(\mathrm{P}<0.05)$. The expression levels of the oxidative stress pathway nuclear factor erythroid 2 (NFE2)-related factor 2 (Nrf2), heme oxygenase-1 (HO-1) and $\mathrm{NAD}(\mathrm{P}) \mathrm{H}$ quinone dehydrogenase 1 (NQO1) mRNA were significantly higher in the experimental group than in the control group. Therefore, the therapeutic
\end{abstract}

Correspondence to: Dr Yinfei Yu, Department of Pharmacy, The Eye Hospital of Wenzhou Medical University, 270 Xueyuanxi Road, Lucheng, Wenzhou, Zhejiang 325003, P.R. China

E-mail: yr74wa@163.com

Key words: diabetic retinopathy, carbamyl erythropoietin, safflor yellow, angiogenic molecules, apoptotic molecules, Nrf-2/ARE oxidative stress pathway molecules effects of CEPO in treating DR are better than those of SY. As a result, CEPO may inhibit apoptosis and oxidative stress damage of retinal tissue cells in DR rats without affecting angiogenesis.

\section{Introduction}

Diabetic retinopathy (DR) is an important manifestation of microangiopathy and is one of the most important causes of blindness in diabetic patients (1). The incidence of retinopathy is as high as $23 \%$ in diabetic patients (2). DR has become the main cause of adult blindness (3). Pathology of DR is mainly the damage of retinal capillary endothelial cells, and changes in expression patterns of angiogenesis, apoptotic and oxidative stress pathway molecules are usually involved $(4,5)$.

Safflor yellow (SY) is the main component of the safflower in Compositae. SY has the function of inhibiting platelet aggregation, antioxidation and tumor growth (6). Recent studies suggest that SY can be used to effectively treat early retinopathy in patients with type II diabetes $(7,8)$. Erythropoietin (EPO) can antagonize oxidation and inhibit apoptosis. On the one hand, EPO reduces damage of retinal nerve cells, and on the other hand, it can promote angiogenesis, leading to the development of the disease (9). Thus, carbamyl erythropoietin (CEPO) loses its ability to promote angiogenesis, but it still maintains other functions (10).

In this study, CEPO and SY were used to treat DR rats and their therapeutic effects were observed. Thus, the molecular mechanism of the action of CEPO in the treatment of DR rats was analyzed. Our study provided reference for further clinical studies.

\section{Materials and methods}

Experimental animals. Healthy adult male SD rats $(200 \pm 20 \mathrm{~g})$ were provided by China Medical University (Taichung, Taiwan, R.O.C.). The rats were kept in cage with controlledtemperature and light cycles $\left(24^{\circ} \mathrm{C}\right.$ and $12 / 12$ light cycles $)$ with free access to water and food. The humidity was $60 \pm 10 \%$. The study was approved by the Ethics Committee of The Eye Hospital of Wenzhou Medical University (Wenzhou, China). The study was approved by the Ethics Committee of The Eye Hospital of Wenzhou Medical University (Wenzhou, China).

Drugs and main reagents. High-fat and high-sugar food (Beijing Botai Hongda Biotechnology Co., Ltd., Beijing, 
China), streptozotocin (Solarbio Science \& Technology Co., Ltd., Beijing, China), CEPO (Jiangsu Tailida Co., Ltd., Rugao, China), SY (state approval no. Z20050594; Shanxi Huahui Kaide Pharmaceutical Co., Ltd., Jinzhong, China), TRIzol (Sangong Pharmaceutical Co., Ltd., Shanghai, China), cDNA first-strand synthesis kit (Sangong Pharmaceutical Co., Ltd.), RT-qPCR kit (Takara Bio, Inc., Otsu, Japan). The primer sequences were synthesized by GenScript (Nanjing, China).

Construction of the diabetes rat model. SD rats were adaptively fed for 1 week, and then fed with high-fat and high-sugar diet for 4 weeks. Intraperitoneal injection of streptozotocin (50 $\mathrm{mg} / \mathrm{kg}$ ) was performed every week after rats were fasted for $12 \mathrm{~h}$. The last injection was performed after the rats were fasted for $8 \mathrm{~h}$. Blood was extracted from the tail vein to detect random blood glucose and blood glucose levels, which were $>17 \mathrm{mmol} / \mathrm{l}$, indicating a successfully established model. A total of 126 DR model rats were obtained.

Animal grouping and drug intervention. One hundred twenty-six rat models were randomly divided into the model $(n=42)$, experimental $(n=42)$ and control $(n=42)$ groups. The rats in the experimental group were treated with intraperitoneal injection of CEPO $(50 \mu \mathrm{g} / \mathrm{kg} \cdot$ day $)$, the rats in the control group were treated with intraperitoneal injection of SY $(40 \mathrm{mg} / \mathrm{kg})$, and the rats in the control and experimental groups were treated for 2 weeks. Finally, the rats in the model group were injected with $1 \mathrm{ml}$ normal saline for 2 weeks.

Measurement of expression levels of angiogenetic, apoptotic and oxidative stress pathway molecules at the mRNA level. After being treated for 2 weeks, the rats were sacrificed and the eyeballs were dissected to obtain retinas. TRIzol was used to extract total RNA from the retinal tissue according to the protocol, and then cDNA was synthesized according to the instructions of the cDNA first-strand synthesis kit. Reverse transcription-quantitative PCR (RT-qPCR) reactions were performed using $\beta$-actin as endogenous control. Expression of angiogenesis-promoting molecules [hypoxiainducible factor- $1 \alpha$ (HIF-1 $\alpha)$, vascular endothelial growth factor (VEGF), angiopoietin (Ang-1)], angiogenesis-inhibiting molecules [tissue kallikrein (TKLK), and pigment epitheliumderived factor (PEDF)], apoptosis-promoting molecules [Bcl-2 related $\mathrm{X}$ protein $(\mathrm{Bax})$ and cysteine aspartate specific protease (caspase-3)], apoptosis-inhibiting molecules (Bcl-2 and survivin), oxidative stress pathway molecules [nuclear factor erythroid 2 (NFE2)-related factor 2 (Nrf2), heme oxygenase-1 (HO-1) and NAD(P)H quinone dehydrogenase 1 (NQO1)] was detected. RT-qPCR reaction system consisted of $10 \mu \mathrm{l}$ of SYBR-Green Master Mix (Takara Bio, Inc., Otsu, Japan), $0.5 \mu \mathrm{l}$ of upstream and downstream primers, $1 \mu \mathrm{l}$ of cDNA,

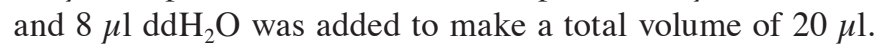
RT-qPCR reaction conditions were: $95^{\circ} \mathrm{C}$ for $3 \mathrm{~min}$, followed by 40 cycles of $95^{\circ} \mathrm{C}$ for $30 \mathrm{sec}$ and $55-61^{\circ} \mathrm{C}$ (depending on specific genes) for $1 \mathrm{~min}$. The primer sequences used in PCR reactions are listed in Table I.

Statistical analysis. SPSS 17.0 (Beijing Xinmeijiahong Technology Co., Ltd., Beijing, China) was used for all statistical analyses. Measurement data were expressed as
Table I. Primer sequences used in PCR reactions.

\begin{tabular}{|c|c|c|}
\hline Genes & Primer sequences $\left(5^{\prime} \rightarrow 3^{\prime}\right)$ & $\left({ }^{\circ} \mathrm{C}\right.$ \\
\hline$H I F-1 \alpha$ & $\begin{array}{l}\text { F: GAACCCATTTTCTACTCAGGACACAG } \\
\text { R: CCACTTTCATCCATTGATTGCCC }\end{array}$ & \\
\hline$V E G F$ & $\begin{array}{l}\text { F: CGAGACCCTGGTGGACAT } \\
\text { R: ACAAATGCTTTCTCCGCT }\end{array}$ & \\
\hline Ang-1 & $\begin{array}{l}\text { F: AGACCAGTACAACACAAAC } \\
\text { R: CGGTCTGAGAGAGGAGGCT }\end{array}$ & \\
\hline$T K L K$ & $\begin{array}{l}\text { F: TCATCAATGAAGACCTATGCG } \\
\text { R: AGCATCAGGTCATTGCTGTA }\end{array}$ & \\
\hline PEDF & $\begin{array}{l}\text { F: CTACAGGTGCGCGCCAAC } \\
\text { R: CTAAGGCGCACACATTTG }\end{array}$ & \\
\hline Bax & $\begin{array}{l}\text { F: GCGAATTGGAGATGAACTGG } \\
\text { R: GTGAGCGAGGCGGTGAGGAC }\end{array}$ & \\
\hline Caspase-3 & $\begin{array}{l}\text { F: GAAGCGAATCAATGGACTCTG } \\
\text { R: GCACAAAGCGACTGGATGAA }\end{array}$ & \\
\hline$B c l-2$ & $\begin{array}{l}\text { F: CTGGTGGACAACATCGCTCTG } \\
\text { R: GGTCTGCTGACCTCACTTGTG }\end{array}$ & \\
\hline Survivin & $\begin{array}{l}\text { F: ATCCACTGCCCTACCGAGAAC } \\
\text { R: TGCTCCTCTATCGGGTTGTCAT }\end{array}$ & \\
\hline$N r f-2$ & $\begin{array}{l}\text { F: TCCTCTGCTGCCATTAGTCA } \\
\text { R: GTGCCTTCAGTGTGCTTCT }\end{array}$ & \\
\hline $\mathrm{HO}-1$ & $\begin{array}{l}\text { F: CAGGAGCTGCTGACCCATGA } \\
\text { R: AGCAACTGTCGCCACCAGAA }\end{array}$ & \\
\hline$N Q O-1$ & $\begin{array}{l}\text { F: GGATTGGACCGAGCTGGAA } \\
\text { R: AATTGCAGTGAAGATGAAGGCAAC }\end{array}$ & \\
\hline$\beta$-actin & $\begin{array}{l}\text { F: GACCCAGATCATGTTTGAGACCTT } \\
\text { R: GACTCGTCATACTCCTGCTTGC }\end{array}$ & \\
\hline
\end{tabular}

F, forward; R, reverse; HIF-1 $\alpha$, hypoxia-inducible factor-1 $\alpha$; VEGF, vascular endothelial growth factor; Ang-1, angiopoietin; TKLK, tissue kallikrein; PEDF, pigment epithelium-derived factor; Bax, Bcl-2 related $\mathrm{X}$ protein; caspase- 3 , cysteine aspartate specific protease; $\mathrm{Nrf}-2$, nuclear factor erythroid 2 (NFE2)-related factor 2; HO-1, heme oxygenase-1; NQO-1, NAD(P)H quinone dehydrogenase 1.

mean $\pm \mathrm{SD}$, and analysis of variance was used for comparisons among groups and the post hoc was Least Significant Difference test. $\mathrm{P}<0.05$ was considered to indicate a statistically significant difference.

\section{Results}

Analysis expression of retinal angiogenesis-related molecules at the $m R N A$ level. After the SY treatment, expression levels of HIF-1 $\alpha$, VEGF and Ang-1 mRNAs in the control group were significantly lower than those in the model and experimental groups $(\mathrm{P}<0.05)$. However, there was no significant difference in the expression levels of the genes in the CEPO-treated experimental and model groups ( $\mathrm{P}>0.05$; Table II). The expression levels of TKLK and PEDF in the control group were significantly higher than those in the model and experimental groups $(\mathrm{P}<0.05$; Table III), while no significant differences were observed between the model and experimental groups $(\mathrm{P}<0.05$; Table III). 
Table II. Expression levels of angiogenesis-promoting molecules in the rat retina at the mRNA level $(n=42$, mean $\pm S D)$.

\begin{tabular}{lccc}
\hline Groups & HIF-1 $\alpha$ & VEGF & Ang-1 \\
\hline Model & $2.42 \pm 0.33$ & $2.35 \pm 0.30$ & $1.80 \pm 0.22$ \\
Experimental & $2.40 \pm 0.31$ & $2.38 \pm 0.28$ & $1.83 \pm 0.25$ \\
Control & $1.85 \pm 0.13^{\text {a }}$ & $1.68 \pm 0.15^{\text {a }}$ & $1.32 \pm 0.15^{\text {a }}$ \\
F & 7.748 & 8.761 & 9.331 \\
P-value & 0.049 & 0.042 & 0.038 \\
\hline
\end{tabular}

${ }^{\mathrm{a}} \mathrm{P}<0.05$, compared with the control and the model groups. HIF- $1 \alpha$, hypoxia-inducible factor-1 $\alpha$; VEGF, vascular endothelial growth factor; Ang-1, angiopoietin.

Table III. Expression levels of angiogenesis-inhibiting molecules in the rat retina at the mRNA level $(n=42$, mean $\pm S D)$.

\begin{tabular}{lcc}
\hline Groups & TKLK & PEDF \\
\hline Model & $0.45 \pm 0.08$ & $0.38 \pm 0.05$ \\
Experimental & $0.48 \pm 0.06$ & $0.35 \pm 0.07$ \\
Control & $0.88 \pm 0.10^{\mathrm{a}}$ & $0.76 \pm 0.03^{\mathrm{a}}$ \\
F & 33.823 & 140.691 \\
P-value & 0.004 & $<0.001$ \\
\hline
\end{tabular}

${ }^{\mathrm{a}} \mathrm{P}<0.05$, compared with the control and model groups. TKLK, tissue kallikrein; PEDF, pigment epithelium-derived factor.

Table IV. Analysis of apoptosis-promoting molecules in the rat retina at the mRNA level $(n=42$, mean $\pm S D)$.

\begin{tabular}{lcc}
\hline Groups & Bax & Caspase-3 \\
\hline Model & $2.88 \pm 0.32$ & $2.51 \pm 0.35$ \\
Control & $2.01 \pm 0.29^{\mathrm{a}}$ & $2.09 \pm 0.24^{\mathrm{a}}$ \\
Experimental & $1.58 \pm 0.18^{\mathrm{a}, \mathrm{b}}$ & $1.70 \pm 0.22^{\mathrm{a}, \mathrm{b}}$ \\
F & 23.632 & 6.463 \\
P-value & 0.001 & 0.032 \\
\hline
\end{tabular}

${ }^{\mathrm{a}} \mathrm{P}<0.05$, compared with the model group; ${ }^{\mathrm{b}} \mathrm{P}<0.05$, compared with the control group. Bax, $\mathrm{Bcl}-2$ related $\mathrm{X}$ protein; caspase- 3 , cysteine aspartate specific protease.

Analysis of expression of the apoptosis-related molecules in the retina. The expression levels of the apoptosis-promoting molecules Bax and caspase- 3 in the retinal tissue of DR rats in the control and experimental groups were significantly lower than those in the model group $(\mathrm{P}<0.05)$, and were significantly lower in the experimental group than in the control group $(\mathrm{P}<0.05$; Table IV). The expression levels of the apoptosis inhibitors Bcl-2 and survivin were significantly higher in the control and experimental groups than in the model group $(\mathrm{P}<0.05)$, and were significantly higher in the experimental group than in the control group $(\mathrm{P}<0.05$; Table $\mathrm{V})$.
Table V. Analysis of apoptosis-inhibiting molecules in the rat retina at the mRNA level $(n=42$, mean $\pm S D)$.

\begin{tabular}{lcc}
\hline Groups & Bcl-2 & Survivin \\
\hline Model & $0.41 \pm 0.05$ & $0.35 \pm 0.04$ \\
Control & $0.61 \pm 0.08^{\mathrm{a}}$ & $0.58 \pm 0.03^{\mathrm{a}}$ \\
Experimental & $0.73 \pm 0.08^{\mathrm{a}, \mathrm{b}}$ & $0.68 \pm 0.03^{\mathrm{a}, \mathrm{b}}$ \\
F & 15.373 & 75.794 \\
P-value & 0.004 & $<0.001$ \\
\hline
\end{tabular}

${ }^{a} \mathrm{P}<0.05$, compared with the model group; ${ }^{b} \mathrm{P}<0.05$, compared with the control group.

Table VI. Analysis of the oxidative stress pathway-related molecules in the rat retina at the mRNA level $(n=42$, mean $\pm S D)$.

\begin{tabular}{lccc}
\hline Groups & Nrf-2 & HO-1 & NQO-1 \\
\hline Model & $1.87 \pm 0.22$ & $1.65 \pm 0.20$ & $1.98 \pm 0.23$ \\
Control & $2.54 \pm 0.19^{\mathrm{a}}$ & $2.88 \pm 0.29^{\mathrm{a}}$ & $2.49 \pm 0.22^{\mathrm{a}}$ \\
Experimental & $2.92 \pm 0.25^{\mathrm{a}, \mathrm{b}}$ & $3.23 \pm 0.28^{\mathrm{a}, \mathrm{b}}$ & $2.91 \pm 0.32^{\mathrm{a}, \mathrm{b}}$ \\
F & 17.304 & 30.606 & 9.583 \\
P-value & 0.003 & 0.001 & 0.014 \\
\hline
\end{tabular}

${ }^{\mathrm{a}} \mathrm{P}<0.05$, compared with the model group; ${ }^{\mathrm{b}} \mathrm{P}<0.05$, compared with the control group. Nrf-2, nuclear factor erythroid 2 (NFE2)-related factor 2; $\mathrm{HO}-1$, heme oxygenase-1; NQO-1, NAD(P)H quinone dehydrogenase 1.

Analysis of the oxidative stress pathway-related molecules in the retina. After treatment, the expression levels of $\mathrm{Nrf}-2, \mathrm{HO}-1$, and NQO-1 in the retina were significantly higher in the control and experimental groups than in the model group $(\mathrm{P}<0.05)$, and were also significantly higher in the experimental group than in the control group $(\mathrm{P}<0.05$; Table VI).

\section{Discussion}

The mechanism of DR is complicated, and it often causes apoptosis of the retinal ganglion cells and damages the nerve function during the disease progression. During the disease development, hypoxia triggers the activation of oxidative stress to further damage the nerve cells. In addition, hypoxia also triggers neovascularization to cause retinal damage, and activates the retinal mitochondrial pathway to induce cell apoptosis and further damages the retina.

Long-term high blood glucose leads to imbalance between pro-angiogenic factors (HIF-1 $\alpha$, VEGF and Ang-1) and anti-angiogenic factors (TKLK and PEDF) $(11,12)$. In particular, the increased level of VEGF promotes the proliferation of the retinal pigment epithelial cells, resulting in increased vascular permeability and retinal exudation, hemorrhage as well as edema $(13,14)$. In this study, SY and CEPO were used to treat DR rats. Results showed that expression levels of HIF-1 $\alpha$, VEGF, and Ang-1 were significantly lower, while the levels of TKLK and PEDF were significantly higher in the SY-treated control group than in the model group $(\mathrm{P}<0.05)$, 
indicating that SY has a certain regulatory effect on the generation of blood vessels. Song et al (15) confirmed that SY may alter the expression of VEGF and PDGF, regulating the process of angiogenesis. There was no significant difference in the expression levels of HIF-1 $\alpha$, VEGF, Ang-1, TKLK and PEDF between the experimental group treated with CEPO and the model group, indicating that CEPO did not affect the angiogenesis of the retina during treatment, thus, resolving the disadvantages of EPO (16).

Retinal hypoxia induces apoptosis by regulating the expression of apoptosis-promoting factors (Bax and caspase-3) and apoptosis-inhibiting factors Bcl-2 and survivin $(17,18)$. Wang et al (17) showed that Bax may increase the release of cytochrome $c$ from mitochondria into cytoplasm and exert a pro-apoptotic effect. Bcl-2 antagonizes Bax by reducing cytochrome $c$ release. In addition, some studies have shown that caspase- 3 is a key molecule at the downstream of cytochrome $c$ (19). Survivin inhibits cell apoptosis by antagonizing the apoptosis cascade mediated by multiple caspase molecules (18). Results of this study showed that compared with the model group, the expression levels of the apoptosis-promoting factors Bax and caspase- 3 were significantly decreased in the experimental and control groups than in the model group, and were also significantly lower in the experimental group than in the control group. The expression levels of $\mathrm{Bcl}-2$ and survivin were significantly higher in the experimental and control groups than in the model group, and were also significantly higher in the experimental group than in the control group, indicating that both SY and CEPO may improve DR by regulating the expression of apoptosis-related factors, and the effects of CEPO are stronger than those of SY.

In addition, retinal hypoxia also triggers the activation of the oxidative stress pathways to increase the levels of oxygen-free radicals, which in turn, damages the nerve cells (19). Nrf acts as a receptor for oxidative stress and plays a major role in the defense against oxidative stress. Nrf 2 has 6 highly conserved domains that can specifically recognize and bind to ARE to form Nrf-2/ARE antioxidant pathway (20), and activation of Nrf2 forms a positive feedback to enhance the regulation of antioxidative stress (21). The binding of Nrf-2 to ARE can activate HO-1 and NQO-1 to remove excess oxygen-free radicals, and reduce stress injury (22). The results of this study showed that the expression levels of oxidative stress molecules were significantly higher in the experimental and control groups than in the model group, indicating that both SY and CEPO may improve the disease conditions by regulating the oxidative stress pathway. The expression level of each oxidative stress molecule in the experimental group was significantly higher than that in the control group, indicating that CEPO is more effective in scavenging oxygen-free radicals than $\mathrm{SY}$.

In conclusion, the therapeutic effect of CEPO in treating DR is better than that of SY. CEPO may inhibit cell apoptosis and oxidative stress damage in the retinal tissues of diabetic rats without affecting angiogenesis.

\section{Acknowledgements}

Not applicable.

\section{Funding}

No funding was received.

\section{Availability of data and materials}

The datasets used and/or analyzed during the present study are available from the corresponding author on reasonable request.

\section{Authors' contributions}

XX drafted this manuscript and helped construction of diabetes rat model. YC and YY performed RT-qPCR. All authors read and approved the final study.

\section{Ethics approval and consent to participate}

The study was approved by the Ethics Committee of The Eye Hospital of Wenzhou Medical University (Wenzhou, China).

\section{Consent for publication}

Not applicable.

\section{Competing interests}

The authors declare that they have no competing interests.

\section{References}

1. Alinia C, Mohammadi SF, Lashay A and Rashidian A: Impact of diabetic retinopathy on health-related quality of life in Iranian diabetics. Iran J Public Health 46: 55-65, 2017.

2. Liu L, Wu X, Liu L, Geng J, Yuan Z, Shan Z and Chen L: Prevalence of diabetic retinopathy in mainland China: A meta-analysis. PLoS One 7: e45264, 2012.

3. Bunce $\mathrm{C}$ and Wormald R: Leading causes of certification for blindness and partial sight in England \& Wales. BMC Public Health 6: 58, 2006.

4. Behl T, Kaur I and Kotwani A: Implication of oxidative stress in progression of diabetic retinopathy. Surv Ophthalmol 61: 187-196, 2016.

5. Calderon GD, Juarez OH, Hernandez GE, Punzo SM and De la Cruz ZD: Oxidative stress and diabetic retinopathy: Development and treatment. Eye (Lond) 31: 1122-1130, 2017.

6. Takahashi Y, Miyasaka N, Tasaka S, Miura I, Urano S, Ikura M, Hikichi K, Matsumoto T and Wada M: Constitution of two coloring matters in the flower petals of Carthamus tinctorius $\mathrm{L}$. Tetrahedron Lett 23: 5163-5166, 1982.

7. Gella L, Raman R, Kulothungan V, Saumya Pal S, Ganesan S and Sharma T: Retinal sensitivity in subjects with type 2 diabetes mellitus: Sankara Nethralaya Diabetic Retinopathy Epidemiology and Molecular Genetics Study (SN-DREAMS II, Report No. 4). Br J Ophthalmol 100: 808-813, 2016.

8. Farshchi A, Aghili R, Oskuee M, Rashed M, Noshad S, Kebriaeezadeh A, Kia M and Esteghamati A: Biphasic insulin Aspart 30 vs. NPH plus regular human insulin in type 2 diabetes patients; a cost-effectiveness study. BMC Endocr Disord 16: 35, 2016.

9. Jo HR, Kim YS and Son H: Erythropoietin and carbamylated erythropoietin promote histone deacetylase 5 phosphorylation and nuclear export in rat hippocampal neurons. Biochem Biophys Res Commun 470: 220-225, 2016.

10. Ding J, Wang J, Li QY, Yu JZ, Ma CG, Wang X, Lu CZ and Xiao BG: Neuroprotection and CD131/GDNF/AKT pathway of carbamylated erythropoietin in hypoxic neurons. Mol Neurobiol 54: 5051-5060, 2017.

11. Coucha M, Elshaer SL, Eldahshan WS, Mysona BA and El-Remessy AB: Molecular mechanisms of diabetic retinopathy: Potential therapeutic targets. Middle East Afr J Ophthalmol 22: 135-144, 2015. 
12. Hampton BM, Schwartz SG, Brantley MA Jr and Flynn HW Jr: Update on genetics and diabetic retinopathy. Clin Ophthalmol 9: 2175-2193, 2015.

13. Liew G, Klein R and Wong TY: The role of genetics in susceptibility to diabetic retinopathy. Int Ophthalmol Clin 49: 35-52, 2009.

14. Hollborn M, Vogler S, Reichenbach A, Wiedemann P, Bringmann A and Kohen L: Regulation of the hyperosmotic induction of aquaporin 5 and VEGF in retinal pigment epithelial cells: involvement of NFAT5. Mol Vis 21: 360-377, 2015.

15. Song $\mathrm{Y}$, Long L, Zhang $\mathrm{N}$ and Liu Y: Inhibitory effects of hydroxysafflor yellow A on PDGF BB induced proliferation and migration of vascular smooth muscle cells via mediating Akt signaling. Mol Med Rep 10: 1555-1560, 2014.

16. Li D, Deng L, Xie X, Yang Z and Kang P: Evaluation of the osteogenesis and angiogenesis effects of erythropoietin and the efficacy of deproteinized bovine bone/recombinant human erythropoietin scaffold on bone defect repair. J Mater Sci Mater Med 27: 101, 2016

17. Wang XL, Yu T, Yan QC, Wang W, Meng N, Li XJ and Luo YH: AGEs promote oxidative stress and induce apoptosis in retinal pigmented epithelium cells RAGE-dependently. J Mol Neurosci 56: 449-460, 2015.

18. Liu N, Zhao N, Chen L and Cai N: Survivin contributes to the progression of diabetic retinopathy through HIF-1 $\alpha$ pathway. Int J Clin Exp Pathol 8: 9161-9167, 2015.
19. Olivares-Gonzalez L, Martinez-Fernandez de la Camara C, Hervas D, Marin MP, Lahoz A, Millan JM and Rodrigo R: cGMP-phosphodiesterase inhibition prevents hypoxia-induced cell death activation in porcine retinal explants. PLoS One 11: e0166717, 2016

20. Lu MC, Ji JA, Jiang ZY and You QD: The keap1-Nrf2-ARE pathway as a potential preventive and therapeutic target: An Update. Med Res Rev 36: 924-963, 2016.

21. Stewart D, Killeen E, Naquin R, Alam S and Alam J: Degradation of transcription factor Nrf2 via the ubiquitin-proteasome pathway and stabilization by cadmium. J Biol Chem 278: 2396-2402, 2003.

22. Park SY,Kim YH and Park G: Cucurbitacins attenuate microglial activation and protect from neuroinflammatory injury through Nrf2/ARE activation and STAT/NF- $\kappa$ B inhibition. Neurosci Lett 609: 129-136, 2015.

This work is licensed under a Creative Commons Attribution-NonCommercial-NoDerivatives 4.0 International (CC BY-NC-ND 4.0) License. 